\title{
En el tercer centenario de Juan Ruiz de Alarcón
}

\section{Origen y fecha de su nacimiento}

El día cuatro de agosto próximo se cumplirán trescientos años de la muerte del más grande de los escritores que ha producido México: Juan Ruiz de Alarcón, universalmente apreciado por su ingenio. La conmemoración de su tránsito deberá iniciarse con la redacción de una biografía que contenga los datos más precisos de su vida que hasta ahora son conocidos y se despoje de la fantasía, que por desgracia ha iluminado la vida del autor con rasgos que no le pertenecen. Todas las biografías que corren del gran comediógrafo se basan, en la magna obra, para su tiempo, premiada por la Real Academia Española, de don Luis Fernández-Guerra y Orbe, titulada $D$. Juan Ruiz de Alarcón y Mendoza, que salió a luz en iel año de r87r. Posteriormente ha sido rectificada en muchos de sus capítulos por los descubrimientos de don Nicolás Rangel, que se consignan en el Boletín de la Biblioteca Nacional de México, números correspondientes a los meses de marzo y abril de 1913 y noviembre y diciembre de I9I5. Por último, arrojan mucha luz sobre rincones obscuros de la vida de don Juan, las investiga- 
ciones hechas en el Archivo de Indias de Sevilla por la diligente y erudita profesora norteamericana Dorothy Schons, que sirvieron de base para su tesis doctoral en la Universidad de Chicago y fueron editadas con el modesto título de Apuntes y documentos nuevos para la biografía de Juan Ruiz de Alarcón y Mendoza, Madrid, i929. La coordinación de todos los nuevos datos que aparecen en estas publicaciones y los razonamientos que se puedan hacer en torno a ellos, nos inducen a modificar fechas que hasta ahora se repiten en los tratados de literatura como cercanas a la realidad y a interpretar hechos en forma distinta a la que ha sido considerada hasta ahora. Intentaremos, pues, una corrección a la biografía del autor de La verdad sospechosa, en puntos substanciales.

Desgraciadamente no puede fijarse día y año de su nacimiento, por desconocerse la partida de bautismo, que no ha sido encontrada a pesar de la diligente búsqueda de los eruditos que se han ocupado de esta materia. Se han señalado los años de I580 a I58I, como probables del nacimiento de don Juan. Así lo establece, don Francisco Rodríguez Marín en un artículo publicado en la Unión Ibero-americana, de los meses de mayo y junio de I9II. Se basa para ello en lo afirmado por uno de los dos testigos que presentó Ruiz de Alarcón a la Casa de Contratación de Sevilla, en I607. Rangel afirma, basaclo en doct1mentos fehacientes, que se inscribió en la Universidad para el estudio de Artes en I592 - es decir, a los once años de edad, en tanto que su hermano Pedro se inscribe también en la misma Facultad a los diecinueve años en el propio I592-, si es válida, como indudablemente lo es, la conjetura de que nació hacia I573 O I574. A los once años, Juan debería tener aprobados los estudios de latín que eran indispensables para el principio de los de Artes y este aprendizaje requería por lo menos tres años. Para ingresar a las Facultades Mayores, requería Salamanca y también México, dieciocho años; por lo tanto, el ingreso a la de Artes que precedía a las Mayores, era a los catorce años cuando menos y los Estatutos de la Universidad determinan la plena capacidad del estudiante para el ejercicio de ciertos actos ajenòs a su situación a los catorce, precisamente. Pequeño de cue:́- 
po como fué toda su vida, corcovado de añadidura, es imposible que se le admitiera en la Universidad a los once años. Juan es, probablemente, el segundo de los hijos de don Pedro Ruiz de Alarcón y de doña Leonor de Mendoza. La fecha de su nacimiento debe retrotraerse, pues, a los años de I575 ó 1576 .

Otro punto discutible en la biografía de Juan Ruiz de Alarcón es el lugar de su nacimiento. Para don Luis FernándezGuerra y Orbe y para don Nicolás Rangel, no hay duda de que nació en México; así lo manifiesta él en todo momento.

Así lo afirma en documentos públicos que hacen prueba plena. Sin embargo... Pedro nació en Tasco; de otro de sus hermanos consta que nació en Tasco. Los padres deben de haber abandonado las minas hacia I58r, para transladarse definitivamente a México.

Las minas iban perdiendo su importancia, agotábanse las vetas y el trabajo se hacía difícil y penoso. En I58I había sólo cuarenta y siete mineros y como setenta personas tratantes $y$ oficiales, sin contar los mayordomos y otros criados.

Si aceptamos la precocidad de Alarcón, es indudable que fué el menor de los hermanos y pudo nacer en México; si pensamos que pudo ser el segundón de la familia por las razones anteriormente expresadas, consideramos muy difícil que la madre de Alarcón pudiera transladarse a México para el sólo efecto de dar al mundo al gran escritor, en una época en que el viaje a Tasco era indudablemente tan difícil, y sobre todo para una mujer, como ir a la propia China. ¿Ha mentido, pues, un hombre tan veraz como el creador del don García, en un punto de tan capital interés? Indudablemente no. He aquí una explicación de lo afirmado por él constantemente. Las minas de Tasco sufrieron un eclipse, como hemos visto, a fines del siglo XVI. Volvieron a tener importancia desde el auge que enriqueció a don José de la Borda. Hablar en documentos oficiales y en España de un lugar reducido a unos cuantos pueblos de indios, era no darse a entender por los oyentes. Además, si Juan Ruiz de Alarcón fué hombre verídico, también fué un caballero muy pagado de sus timbres de nobleza; alardeó siempre de sus antepasados; sentó plaza de hidalgo notorio. El lugar de ori- 
gen era importante en la genealogía, y confesemos que no era lo mismo llamarse hijo de México, capital de la Nueva España, que originario de Tasco o mejor de Tenango, Tetípac, Tetelcingo, o cualquiera de los lugarejos que componían el Real de Minas en el siglo XVI. Entendiendo la psicología del mexicano, se puede fácilmente comprender el porqué de una afirmación que no dañaba a nadie y que era, además, verídica en cierto sentido, puesto que la Vicaría de Tasco formaba parte de la arquidiócesis que gobernaba el Arzobispo de México, prolongación, por lo tanto, de la capital de la Nueva España.

\section{II}

\section{La juventud del poeta}

No quedan, tampoco, huellas de los acontecimientos que se sucedieron en la juventud del dramaturgo en el Virreinato de la Nueva España. Una referencia a un Virrey, una mención de un suceso de trascendencia en la vida de México y nada más. $Y$, sin embargo, importantes fueron ciertos hechos que deben haber conmovido hondamente a los habitantes de una ciudad de corta población como lo era México al finalizar el siglo XVI. Desde luego, ciertas dificultades que movieron gran alboroto entre las órdenes monásticas, allá por el año de ${ }^{5} 586$. Gobernaba a la sazón el Virreinato don Alonso Manrique de Zúñiga, Marqués de Villa Manrique, y se dió una disposición para secularizar el adoctrinamiento de los indígenas. Las órdenes monásticas bien organizadas ya, y poderosas aunque recientemente establecidas, protestaron por tal decreto apoyadas por los indios que estimaban más a los frailes que a los sacerdotes seglares. Los provinciales de los franciscanos, de los agustinos y de los dominicos reclamaron al Virrey y mantuvieron firmemente sus demandas obligando al Virrey a ceder. Gran revuelo debe haber producido también en la tranquila ciudad de México la noticia del asalto de un galeón, cerca de las costas de la California por el pirata inglés Cavendish y el posterior secuestro del 
Santa Ana, cargado de oro y mercancías que iba rumbo a China, perpetrado por el célebre pirata Drake en las costas del $\mathrm{Pa}$ cífico. ¡Habría que oir los comentarios de los buenos burgueses en los corrillos del portal de Mercaderes o del Cabildo! Más grave fué aún, lo que sucedió en el año de I 588, al disputar el Virrey con la audiencia de Guadalajara por cuestiones de jurisdicción, pues llegó a organizarse un grupo expedicionario que, en son de guerra, marchó hacia el reino de la Nueva Galicia con ánimo de tomar posesión de las villas y poblados que reclamaba como suyos la Audiencia. Tal fué el escándalo que se produjo y los ecos de él llegaron de tal manera abultados a la Majestad de Felipe II, que se pensó en una sublevación del Reino y se dictaron medidas urgentes para remediar la situación. Desde luego y, como era de rigor, se nombró un visitador que viniera a poner en claro lo sucedido y el nombramiento recayó en el obispo de Tlaxcala, don Pedro Romanos; se abrió juicio de residencia al Virrey y tan solícito anduvo el pesquisidor que, según cuentan las crónicas, embargó hasta la ropa blanca de la señora Virreina. Tuvo, sin embargo, el caído oportunidad de conversar con el que le sucedía en el mando, en el convento de Acolman para retirarse después a Texcoco a esperar el fin de sus desdichas, que vino con la muerte en Madrid sin que se le hubiera restituido en la posesión de sus bienes a pesar de lo. mandado por el Rey.

El recién llegado a México era embajador en Florencia, don Luis de Velasco, antiguo vecino de la ciudad, con bienes propios en ella y encomienda en Tultitlán, hijo del segundo Virrey, don Luis de Velasco, de grata memoria, y padrino de bodas del matrimonio Alarcón y Mendoza.

Natural sería que a la recepción del Virrey la familia de D. Juan Ruiz de Alarcón haya concurrido. Más, que su entrada a México fué de las más lucidas y vistosas que presenciaron los buenos habitantes hasta entonces y las actividades de la colonia se paralizaron por varios días. Cuéntase que hubo hasta un serio resquemor entre los regidores de la ciudad por una cuestión del protocolo. Querían la precedencia en el desfile los relatores y secretarios de la Audiencia y los señores del 
Cabildo alegaban que una cédula Real se las daba a ellos. Disputaron ambas partes ante el Virrey, quièn dejó las cosas en tal estado, prometiendo estudiar el asunto a fondo para más tarde y el 25 de enero de 1589 , poco después de las tres de la tarde entró a la ciudad en medio de muy lucido cortejo. A la vanguardia marchaba un piquete de soldados - cuentan las crónicas- con su música militar; los maceros del Ayuntamiento venían después, con sus trajes de terciopelo carmesí y sus mazas de plata apoyadas al hombro. Después, el alguacil de la corte y el de la ciudad, los relatores y secretarios de la Audiencia y a los lados del Virrey y llevando las riendas de su caballo, el corregidor y un Alcalde ordinario a la izquierda, y otro Alcalde y el Alguacil Mayor, don Diego de Velasco, a la derecha. Tras él y a caballo, también, los principales vecinos de la ciudad.

E1 gobierno de don Luis de Velasco se caracterizó por la ilimitada protección que dió a los indios. Quiso acabar con las dificultades de frontera y envió cuatrocientas familias tlaxcaltecas, para mezclarse, que no se mezclaron, con los rebeldes y bravíos chichimecas y de ello nació la fundación de San Luis Potosí y de otras cuatro colonias: San Miguel, Mesquitic, San Andrés y Colotlán. Nombró abogados que defendieran gratuitamente a los indios. Atendió a la colonización del reino de Quivira, llamado posteriormente Nuevo México, dándole al capitán nombrado para ello, D. Juan de Oñate, seis mil pesos en préstamo y cuatro mil para gastos. Extendióse la jurisdicción del Virreinato de la Nueva España a las Islas Filipinas nombrando D. Luis a Gómez Pérez de las Mariñas como Gobernador del Archipiélago. La ciudad ganó un paseo, la Alameda, en cuyo centro puso don Luis una fuente. De ahí en adelante fué el paseo predilecto de damas y caballeros en la colonia. Indudablemente por sus callecillas debe haber paseado D. Juan, tal vez del brazo de su hermano don Pedro, repasando la lección que deberían más tarde explicar en las cátedras que seguían por entonces, año de 1593, en la Facultad de Artes de la Universidad.

La familia de Alarcón debe haber sentido de corazón, el 
translado del amigo al Virreinato del Perú. Aunque, por otra parte, padre e hijos se inclinarían a felicitar al Virrey ya que su designación constitúa un ascenso.

Breve paréntesis de don Gaspar de Zúñiga y Acevedo, Conde de Monterrey ( 5 de noviembre de 1595 a octubre de I603) en el que se sucede una expedición a las Californias al mando de Sebastián Vizcaíno, con la fundación de la Monterrey de California y de la Monterrey del Nuevo Reino de León; la muerte de Felipe II que cubre de luto a la ciudad en I598; el ascenso al trono de Felipe III; los viajes del Virrey a los mercados de Santiago Tlaltelolco y de San Juan para presenciar, en persona, los ajustes de los indios que deberían formar parte de las congregaciones y el translado de la Villa Rica de la Veracruz de la antigua al sitio fundado por Cortés. Por ahí sale hacia mil seiscientos don Juan Ruiz de Alarcón a España para regresar hacia I608, en los momentos en que el amigo de la familia don Luis de Velasco, ya marqués de Salinas, se ocupaba de la magna obra del desaguie del Valle de México.

Las inundaciones eran frecuentes, las aguas de la laguna se encontraban sin salida. Se la buscó por Huehuetoca. Para ello era menester gastar crecidas sumas y el Virrey recurrió a una contribución del uno por ciento sobre los bienes, muebles e inmuebles de los habitantes de la ciudad que fueron valuados en 2.267,555 pesos; el impuesto produjo 304,013 pesos que aportaron particulares y congregaciones, excepto los franciscanos. Dirigen los trabajos el P. Juan Sánchez, de la Compañía de Jesús y Enrico Martín. El 7 de mayo corrieron por primera vez las aguas por el tajo de Nochistongo. Se emplearon 47 I, I 54 . operarios.

Don Juan Ruiz de Alarcón recuerda tan magno acontecimiento en su obra El semejante a sí mismo. Después de la sucinta descripción de la ciudad, Leonardo, uno de los personajes, reputa las obras como una de las maravillas del mundo y dice que la laguna creció

$$
\begin{aligned}
& \text { el año que se contaba } \\
& \text { mil seiscientos y cinco } \\
& \text { hasta entrarse por las casas; }
\end{aligned}
$$


En aquel siglo dorado (dorado, pues gobernaba el gran Marqués de Salinas, de Velasco heroica rama, símbolo de la prudencia, puesto que por tener tanta, después de tres Virreinatos vino a presidir a España), trató este nuevo Licurgo, gran padre de aquella patria, de dar paso a estas crecientes que ruina amenazaban; y después de mil consejos de gente docta y anciana, cosmógrafos y alarifes de mil medidas y trazas, resuelve el sabio Virrey que por la parte más baja se dé en un monte una mina de tres leguas de distancia, conque por el centro dél hasta la otra parte vayan las aguas de la laguna a dar a un río arrogancia. Todo es uno el resolver y empezar la heroica hazatia: mil quinientos peones continuamente trabajan. En poco más de tres años concluyeron la jornada de las tres leguas de mina, que la laguna desagua. Después, porque la corriente humedeciendo cavaba el monte, que el acuedicto cegar al fin amenaza, de canteria inmortal de parte a parte se labra, que da eterna paz al reino y a su autor eterna fama.

Como para el pago de los gastos se gravó, principalmente, el vino, el gracioso de la comedia, Sancho, exclama: 
¿Que la bellaca del agua quiso alzarse con la tierra?

Pues el vino ¿¿ónde estaba?

A lo que replica Leonardo:

Trazando como a su costa
se efectuase esta hazaña;
que dos reales impuestos
en cada azumbre dél, daban
cada año eran mil ducados,
que en el desagüe se gastan.

Así don Juan Ruiz de Alarcón, ya en Madrid, rendía tributo de gratitud al amigo de su familia y se congraciaba con él para alcanzar favor en lo que entonces pretendía.

\section{III}

\section{Su experiencia universitaria}

Más económica resultaba la obtención del grado de Doctor en la Universidad de México que en la de Salamanca; sin embargo, era menester realizar algunos gastos, excesivos para un hombre pobre, como lo era don Juan Ruiz de Alarcón y Mendoza, según declaración propia que se expresará líneas adelante. La recepción de un Doctor era motivo de gran atención en la colonia. El vejamen, como se llamaba a uno de los capítulos de la colocación del grado, representaba en la tranquila ciudad un motivo de holgorio. Los Estatutos de la Universidad señalaban minuciosamente los diferentes actos a que estaba sujeta la recepción que, en términos generales, era semejante a la que prescribía la salmantina. El principal número del programa era el paseo que el candidato, las autoridades universitarias, el claustro de doctores y gente de importancia en la ciudad efectuaban precisamente la víspera de la obtención del grado que debería otorgarse con "pompa y majestad", "así de acompañamiento como de trompetas, chirimías, y atabales, saliendo el día señalado a las dos de la tarde de casa del Doctorando a donde 
todos los doctores han de ser obligados a acudir a caballo con sus capirotes e borlas".

La organización de la comitiva era la siguiente: los atabaleros delante vestidos con sus ropas de costumbre, lo mismo las trompetas y chirimías, después los bedeles de la Universidad, a caballo, y con sus mazas al hombro; en seguida el maestro de ceremonias y el secretario del claustro y de dos en dos los maestros en Artes por orden de antigüedad y después de los artistas los doctores médicos, teólogos, canonistas, legistas; el fiscal, alcaldes y oidores de la Real Audiencia que tuvieren grado en la Universidad; a continuación e inmediatamente después el doctorando, con el Rector a la derecha y su padrino a la izquierda, "y detrás de él ha de ir un hombre de armas en un caballo a la brida bien aderezado que lleve un bastón dorado, la borla, el bonete o gorra según fuere el estado del doctorando y en su acompañamiento lleve los lacayos y pajes con sus libreas".

La comitiva marchaba a casa del maestrescuela, quien se incorporaba a la procesión colocándose a la derecha del Rector y dejando que el principal actor de la fiesta se acompañara con su padrino. Recorrían las principales rúas de la ciudad hasta dejar nuevamente al maestrescuela en su casa.

Al día siguiente a las ocho de la mañana en punto "con la misma pompa e orden e solemnidad se torne a acudir a casa del doctorando... y vayan a casa del maestrescuela y de allí... en forma referida a la casa del muy excelentísimo señor Virrey si se hallare en el grado, lo cual siempre procure la Universidad, e le acompañen a la catedral de esta ciudad".

Ahí en la nave colateral del Evangelio se levantaba un tablado con sillas para el claustro y en una mesa las insignias doctorales de espada y espuela para los seglares, anillo y libro para los eclesiásticos y una cátedra pequeña donde tomaba asiento el candidato y, a su lado, el padrino. Terminada la misa que con gran devoción se cantaba, el que recibía el grado debía responder a una cuestión que le proponía el maestrescuela, sobre un tema de su facultad, y después a otra del Rector, no respondiendo a otras que le argiuían dos de los doctores presentes. 
A continuación seguía el vejamen hecho "con gracia y donaire", diciéndole cosas ridículas pero cuidando que las personas encargadas de ello "ni apoden, ni digan, cosa que lastime ni cause sentimientos, sino solo se acuda al fin que es vejar al laureando, conforme al uso e práctica común en las universidades insignes. E para el dicho vejamen dé el laureando veinte pesos e no más".

Pedido y obtenido el grado, el padrino procedía a darle las insignias ciñéndole la espada y calzándole las espuelas como caballero y el anillo y el libro siendo eclesiástico y terminando por darle el ósculo. Ante el maestrescuela prestaba el nuevo doctor juramento de fe para en seguida recibir la borla, con lo que se consideraba concluída la ceremonia. Venían después los parabienes, el besamano del. Virrey, los abrazos de los colegas y el retiro de cada quien a su casa en el orden de la procesión que se tuvo para recogerlos.

A diferencia de Salamanca, el Estatuto de la Real y Pontificia Universidad de México prescribe que "no se den comidas ni colaciones". Pero sí había propinas que alcanzaban una buena cantidad de dinero y que se repartían como sigue: cincuenta y ocho pesos al maestrescuela más la propina del grado si el doctorante fuere de distinta facultad; cincuenta y ocho al padrino, veinticinco al arca de la Universidad; al Rector la misma que a cualquier doctor de la facultad por el acompañamiento y paseo y además lo que le perteneciere si fuere doctor; diez. y siete pesos a los doctores; diez y nueve pesos y medio al Secretario de la Universidad; dos y medio a los bedeles; siete al maestro de ceremonia; cinco al alguacil, sin contar otras propinas adicionales por lo que "se les hubiere quitado de la propina del grado de licenciamiento".

No estando Juan Ruiz de Alarcón en posibilidad de pagar todos los gastos, solicitó del claustro pleno de la Universidad que se reunió a los doce días del mes de mayo de ío9 que se le dispensara de la pompa para recibir el grado de Doctor en atención a ser tiempo de cuaresma y ser el solicitante "tan pobre como consta a su señoría". Nemine discrepante otorgaron los señores del claustro lo pedido por Juan Ruiz y por el Lic. Pedro 
Cano que hizo idéntica solicitud. A pesar de ello Juan Ruiz de Alarcón no obtuvo nunca el grado apetecido.

Sus relaciones con la Universidad no se interrumpen: ambiciona ser profesor de la ilustre Academia e intenta, en varias ocasiones, alcanzar alguna de las cátedras que se leen para la enseñanza del Derecho Civil o Canónico. Para ello tiene que concurrir a las oposiciones que conforme a los Estatutos son indispensables para cubrir cualquier vacante y stujetarse en todo a lo que prescriben los reglamentos sobre el particular, o sea; permanecer en sus casas durante el tiempo que dure la oposición y salir sólo con licencia del Rector; no entrar a casa de ninguna persona que fuere voto en la oposición, "ni darle por si o por interposita persona, dinero ni indirectamente dinero, comida, almuerzo, colación, ni depositar con ella plata, oro o dinero que lo valga en poca o mucha cantidad"; dar las fianzas requeridas y leer a su tiempo los puntos de oposición en los libros que se usan para explicar regularmente la lección: Decretales, Decreto y Clementinas para las de Derecho Canónico; Código e Instituta para las Leyes. Después de la asignación de los puntos, presentar las conclusiones para que le arguyan en la facultad y someterse a la votación de los esturdiantes que hayan escuchado las lecciones de los opositores y que debían tener ciertas y determinadas condiciones. Para votar en Leyes y Cánones se requerían ocho años, cuando menos, de matrícula en la respectiva facultad y si ya fueren graduados bachilleres podían votar también si concurrían a un curso de la Universidad. Estas reglas se establecían "por ctanto resultan grandes inconvenientes de que los estudiantes asistan solo en la Universidad por votar cátedras, sin aprovechamiento ninguno en las letras haciéndose cuadrilleros y caudillos de los demás que han de votar" y para tener a raya a estos capitanes y cuadrilleros se les quita el derecho al voto, así como a los que "dieren grita, hablando palabras descompuestas, malsonantes y escandalosas a las personas de cualquier estado que sean que entraren a oir las lecciones y asistir en el dicho general" a la oposición. La votación se hacía por cédulas que se ensartaban en tantas agujas cuantos fueren los concursantes. 
En el año de r6og vacó la cátedra de Instituta y se oponen a ella los doctores Pedro Garcés Portillo, y Bricián Diez Cruzate, viejo amigo de Juan Ruiz en Salamanca y compañero en el viaje de retorno, y el licenciado Cristóbal de Hierro Guerrero y los bachilleres Jerónimo de Sedano y Antonio de Roque, habiéndola obtenido el primero por un excedente en votos de seis $y$ veintinueve cursos aprobados. Porque se tenían en cuenta en la votación los cursos llevados por los votantes en la Factitad.

Por el ascenso del Dr. Garcés queda vacante la de Decreto $\mathrm{y}$ se oponen a ella los doctores Pedro Cano, Damián Gentil de Párraga, el licenciado del Hierro Guerrero, y el bachiller Jerónimo de Sedano, obteniendo la cátedra el licenciado Cristóbal del Hierro por tuna diferencia de dieciséis votos y sesenta y cuatro cursos aprobados. Juan Ruiz de Alarcón, que se opone también a ella, queda en último lugar con nueve votós y cincuenta y siete cursos, frente a cuarenta y nueve y doscientos cuarenta y siete que obtiene el triunfador. La cátedra se proveyó el 9 de noviembre del año citado de I6o9.

Por último en I6r 3 queda vacante la cátedra temporal de Cánones por ascenso a otra del doctor Luis de Cifuentes; toman parte en la oposición los doctores Cristóbal del Hierro, Bricián Diez Cruzate, Pedro Garcés, el maestro Francisco Sánchez y Juan Ruiz de Alarcón y vuelve a ganarla el doctor Pedro Garcés del Portillo, quien al abandonarla, deja la cátedra temporal de Instituta que obtiene el amigo de Alarcón Bricián Diez. Cruzate con treinta votos y setenta y dos cursos quedando otra vez en último lugar el que había de ser uno de los autores dramáticos más grandes de España.

Esta última provisión no fué muy pacífica que digamos, ya que Juan Ruiz de Alarcón se dirige al claustro diciendo en los documentos publicados por Rangel, "que a su noticia ha venido que muchos de los votos que han de ser en esta cátedra de Instituta, a que estoy opuesto, se les hacen amenazas sobre que no voten por algunos de los opositores, y los dichos votos aunque se vota secretamente votan con miedo, y la causa es porque como hay poco número de votos son muchos de ellos conocidos 
en el número de cursos y calidades" y pide que cada voto se manifieste en dos cédulas de cada opositor y así no puedan ser conocidos los votantes. Otro de los opositores, el licenciado Sedano, a su vez manifiesta "que ha llegado a su noticia que el Dr. Cruzate contraviniendo a los reales Estatutos ha dado en la oposición de la cátedra de Código y en ésta a que está opuesto a. votos, preseas, dineros, colaciones, cenas y otras cosas por lo cual ha quedado inhábil e incapaz para esta oposición y las demás de esta Universidad que en adelante se ofrecieren". Como a su vez el Dr. Cruzate alegó falta de personalidad al opositor Sedano para acusarlo ante el claustro, Juan Ruiz de Alarcón manifiesta que todos sus contrincantes han incurrido en inhabilidad, de acuerdo con lo que los propios autos descubren y pide se le declare catedrático de la vacante.

Por otra parte, el Dr. del Hierro arguye que se le dió posesión de la cátedra al Dr. Cruzate ocultamente, pues el acto se efectuó a las tres de la mañana y pide se declare la nulidad del mismo. El pleito se sigue en la Audiencia por los apoderados de cada uno de los opositores: Gil de Vitores por el Dr. del Hierro; Leonardo Salazar por el Lic. Agustín de Sedano, y Pedro Franco y Diego de Villagrán por Juan Ruiz de Alarcón.

Mucho se ha fantaseado sobre las causas que motivaron el fracaso de Juan Ruiz de Alarcón en las oposiciones de la Universidad. Don Luis Fernández-Guerra supone que en gran parte tuvo que ver en ello su figura. "Poco feliz - dice- en sus ambiciones universitarias... o por mayor habilidad de los contrincantes o por el fatal inconveniente de la joroba". La averiguación anteriormente bosquejada hace plena luz. En la Universidad de México, como en la de Salamanca, como en todas, la provisión de cátedras será motivo de verdadera agitación entre estudiantes y profesores. Dominicos y agustinos hacían uso de todas las armas, legítimas e ilegítimas, para alcanzar el triunfo en Salamanca. Los Estatutos de la Universidad de allá y de acá son extraordinariamente minuciosos en las disposiciones que contienen para evitar la presión, la amenaza, el cohecho, signo evidente de que existían tales contingencias en un grado apreciable. Se encerraba a los opositores para evitar su 
comunicación con los votantes, se les vigilaba constantemente, se castigaba cualquier acto que pudiera suponer contravención a lo estatuído. A pesar de ello, el cohecho y la amenaza existía. Juan Ruiz luchaba con armas desiguales en estas competencias. Sus rivales o tenían arraigo en la Universidad como el Dr. del Hierro, o eran hombres ricos como su amigo el Dr. Cruzate. Buena parte del éxito se aseguraba por el trato diario con los estudiantes, en el desempeño de cátedras o en el trámite de asuntos relacionados con la Academia; la gentil presencia y el oro repartido discretamente ganaban con facilidad una bata1la. Don Juan Ruiz de Alarcón llegaba de España, sus relaciones con antiguos maestros y condiscípulos se habían enfriado; contaba, ciertamente, con algún apoyo de importancia en viejos maestros como don Juan de Salcedo, en personas de cierto valimiento como el Dr. Luis de Cifuentes, abogado de la Audiencia y más tarde consultor de la Inquisición y asesor general del Virrey Marqués de Gelves, pero no contaba con buenas relaciones entre los estudiantes de !a Universidad que eran los que votaban. Su natural hidalgo y caballeresco repugnaba, indudablemente, con las pequeñas intrigas que era necesario poner en juego para alcanzar una cátedra. Debió convencerse entonces, que el saber no lo era todo, antes el dinero, la amenaza, la promesa del éxito fácil en la cátedra que el estudiante seguía. Armas que se esgrimieron entonces como ahora. ¿¿ Cuántos catedráticos han llegado así a todas las Universidades del mundo? Interesante lección para el que había de ser, andando el tiempo, un maestro de moral en el teatro.

Julio JIḾ́nez RuedA. 
